\title{
Criterion-Related Validity of a Simple Muscle Strength Test to Assess Whole Body Muscle Strength in Chinese Children Aged 10 to 12 Years
}

\author{
Liqin Yin $\mathbb{D}^{1,2}$ Changfa Tang $\mathbb{D},{ }^{1}$ and Xia Tao ${ }^{3}$ \\ ${ }^{1}$ Department of Physical Education, Hunan Normal University, Lusan North Road, Changsha, Hunan 410082, China \\ ${ }^{2}$ Department of Physical Education, Hunan University of Technology, Taishan Road, Zhuzhou, Hunan 412008, China \\ ${ }^{3}$ Department of Physical Education, Hunan Business College, XiaJiaHu Road, Changsha, Hunan 410089, China \\ Correspondence should be addressed to Changfa Tang; 1104755704@qq.com
}

Received 25 August 2017; Revised 27 November 2017; Accepted 18 December 2017; Published 18 January 2018

Academic Editor: Zan Gao

Copyright (C) 2018 Liqin Yin et al. This is an open access article distributed under the Creative Commons Attribution License, which permits unrestricted use, distribution, and reproduction in any medium, provided the original work is properly cited.

\begin{abstract}
Objective. To study the criterion-related validity of simple muscle strength test (SMST) indicators and assess whole body muscle strength in Chinese children aged 10 to 12 years old. Methods. Two hundred and forty children were equally divided into four groups in different genders and residences. The SMST indicators (hand-grip, knee bent push-up, back muscle strength, sit-up, leg muscle strength, and standing long jump) were tested. We set up the total level of the whole-body muscle strength $\left(F_{\text {total }}\right)$ through testing isokinetic muscle strength of the six joints' flexion and extension movements. Pearson correlation analyses were used to analyze the correlation between the SMST indicators and the $F_{\text {total }}$. Results. (1) Leg muscle strength and back muscle strength demonstrated the highest validity scores. Sit-ups, hand grip, and standing long jump demonstrated the lowest validity scores. (2) Leg muscle strength had the highest validity for males, but back muscle strength had the highest validity for females. Conclusions. Back muscle strength and leg muscle strength can give the highest validity of assessing whole body muscle strength, and also has higher validity in both the urban and rural children. For urban children, but not rural, the knee bent push-up also has a high validity indicator.
\end{abstract}

\section{Introduction}

The effectiveness of strength-related quality in daily life, exercise, and prevention and treatment of chronic diseases has increasingly been recognized $[1,2]$. As a result, strength quality is included in the physical fitness tests as an essential test in many regions, worldwide $[3,4]$. Strength tests are an important component of physical fitness tests in many countries and regions in the current world. The simple muscle strength test (SMST), an important strength quality test, typically uses simple force, range, and speed measuring devices to measure the strength of muscles in static and dynamic states. These low-cost and portable devices are an appropriate and convenient method to assess muscle strength during physical fitness tests. Fan et al. [5] reviewed eleven physical testing systems across seven countries/regions and found that there were eighteen indicators of SMST. The most commonly used SMST indicators of physical fitness tests in
Chinese children aged 10-12 years are hand-grip, knee bent pull-up, back muscle strength, leg muscle strength, standing long jump, and sit-up.

Ample research has been conducted on the criterionrelated validity of SMST test indicators [6-10]. The criterion standard for various tests (1RM test [11], isokinetic muscle test [12], force plates [13], and surface EMG contribution rate [5]) is usually adopted. The validity of the upper limb SMST indicators is more prominent for modified pull-ups, hand-grip, standard push-ups, and bent-knee push-ups [14]. There were three indicators in the test of trunk strength: sit-ups, trunk-lift, and back muscle strength. Standing long jump and leg press are common indicators of lower-body muscle strength; however, research suggests that the leg press is not suitable for large-scale crowd testing [7]. The standing long jump is a basic test of young children's lowerbody strength and is favorable for its utility, time-saving, and economy of use [4]. However, literature [15] suggests 
that the standing long jump has questionable validity against technology, anthropometry, biomechanics, and coordination control factors.

However, there are two main defects in previous studies. Firstly, there were no tests for two or more than two blocks and no single test can assess the overall strength of the body. It is necessary to study the validity of the SMST to reflect the whole body muscle strength. Secondly, residence differences are not considered in the study of validity. Fan et al. [5] further suggested that the indicators of SMST were not unified across countries/regions [16]. The indicator of the same position was different across age and gender. Additionally, there is a place of residency difference in muscle strength tests [17]. The difference of muscle strength of urban and rural adolescents is more obvious [18]. Although gender differences are reflected in the indicators of strength testing, there is less attention to the differences in urban and rural areas.

The aims of the present study, therefore, were to (1) study the criterion-related validity of SMST indicators (hand-grip, knee bent pull-up, back muscle strength, leg muscle strength, standing long jump, and sit-up) to assess whole body muscle strength in Chinese children, aged 10 to 12 years and (2) compare the validity of SMST indicators to assess whole body muscle strength in different genders and residences.

In order to study the validity of SMST indicators to assess whole body muscle strength, we tested the isokinetic muscle strength of the six joints' flexion and extension movements of the whole body. The isokinetic strength test (IST) has been demonstrated to be valid for assessing muscle strength and muscle function in the knee joint $[19,20]$, hip joint [21, 22], ankle joint [23], shoulder joint [24], and trunk [25, 26]. The public factors were extracted by conducting a factor analysis and the total factor score was calculated $\left(F_{\text {total }}\right)$ according to the public factor contribution rate [27]. We set up the total level of the whole body muscle strength $\left(F_{\text {total }}\right)$ and used it as the calibration of whole body muscle strength. Meanwhile, we analyzed the SMST indicators and the $F_{\text {total }}$, and screened out the best index reflecting the whole body muscle strength of children. Pearson correlation analysis was carried out between the SMST indicators and the whole body strength $\left(F_{\text {total }}\right)$ to screen out the best indicator to reflect the muscle strength of the children.

\section{Methods}

2.1. Participants and Design. Fifth and sixth graders, aged 10 to 12 years, were recruited from the Hunan Normal University Affiliated Primary School (Changsha City, urban) and Liuyang Kouchong Primary School (Liuyang, rural) using a stratified random sampling method. In total, 240 students participated in the study and were divided into four groups which were urban boys (UB), urban girls (UG), rural boys (RB), and rural girls (RG). Each group contained 60 students. All participants met the following criteria: (1) aged 10 to 12 years; (2) no history of disease and contraindications; (3) did not participate in high-intensity exercise in the seven days before the test; (4) had no joint, muscle, or bone damage in the first half of the year before the test; (5) carried out adequate preparation activities before the test.

\subsection{Measurements}

2.2.1. Isokinetic Strength Test (IST). The Biodex system 3 is a multijoint, constant velocity testing and training system (Biodex Medical Systems New York, USA) and was used to assess IST in the present study. The test indicators for IST were based on the six joints (shoulder, elbow, wrist, marrow, knee, and ankle) for peak torque (PT) and unit weight torque (UWT). PT is the maximum torque output produced by muscle contraction throughout the joint activity, that is, the highest point of the torque curve [28]. UWT refers to the peak torque of unit weight and can be used to compare the strength of the individual people with different weight $[22,23]$.

Range of motion (ROM), also known as the range of joint activity, refers to the maximum radian that can be achieved during joint activity [24]. There were three types of ROM of the joints, which were $60^{\circ} / \mathrm{s}, 180^{\circ} / \mathrm{s}$, and $240^{\circ} \%$, respectively, standing for slow, medium, and fast test speeds. Due to incomplete muscle development of participants and because the participants could not complete the $60^{\circ} / \mathrm{s}$ test, the current study used the $90^{\circ} / \mathrm{s}$ test. The full range was adopted for motion amplitude. The IST was strictly conducted following the instruction in the manual of Biodex system 3. For each joint, there were three groups of tests and each test was tested three times with 30-second periods of rest between each test. Before the formal test, the submaximal joint flexion and extension exercises were performed to help participants familiarize themselves and adapt to the test. Afterwards, the participants were weighed to correct the effect of gravity on the test results. The sagittal axis of the joint tested was aligned with the axis of the spindle of test equipment. The order of the six joints tested was as follows: hip; shoulder; knee; elbow; ankle; wrist. The upper and lower limb tests were carried out alternately.

2.2.2. Simple Muscle Strength Test (SMST). The introduction of SMST is presented in Table 1. Each test was measured thrice, with 3 to 5 minutes of rest between each test. The best result was recorded.

\subsection{Statistical Analyses}

2.3.1. The Establishment of $F_{\text {total }}$ Based on IST. $F_{\text {total }}$ reflects the overall level of muscle strength of the human body. It was used as a standard of comparison to evaluate the validity of the muscle strength test. The $F_{\text {total }}$ uses a few factors to describe the indicators and the weight of the link between various factors and was closely related to several variables as the same factor, with fewer factors reflecting the original data of general information-establishing a test for muscle strength evaluation and the effectiveness of the standard of comparison. In the current study, $F_{\text {total }}$ was counted through factor analysis of the $90^{\circ} / \mathrm{s}$ PT of IST.

Before conducting the factor analysis, the correlation analyses, Kaiser-Meyer-Olkin (KMO) test and Bartlett test, were used to test whether the data met the criteria for conducting a factor analysis. The Bartlett's sphericity test showed whether the data was suitable for factor analysis. According to the principle of factor analysis, when the 


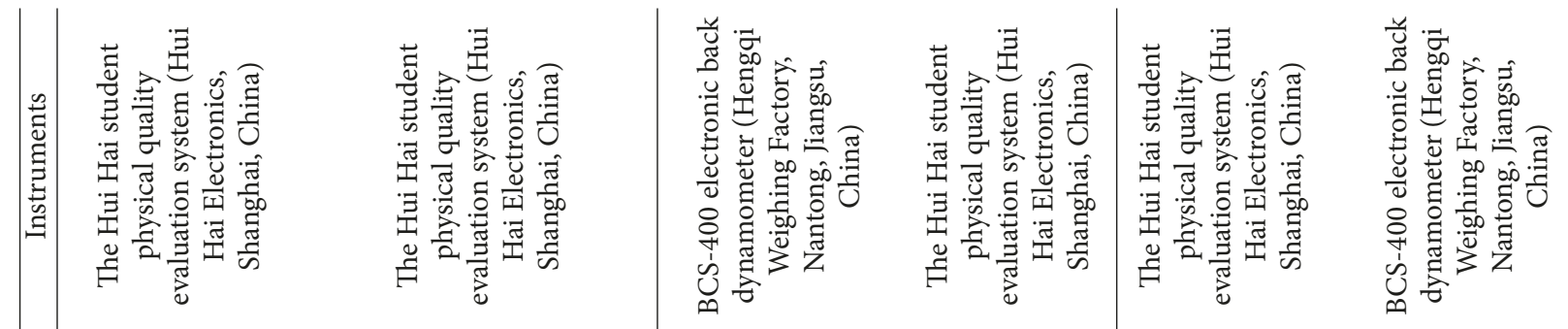

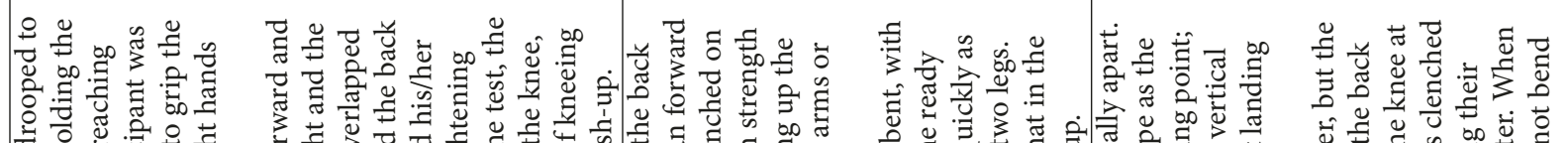

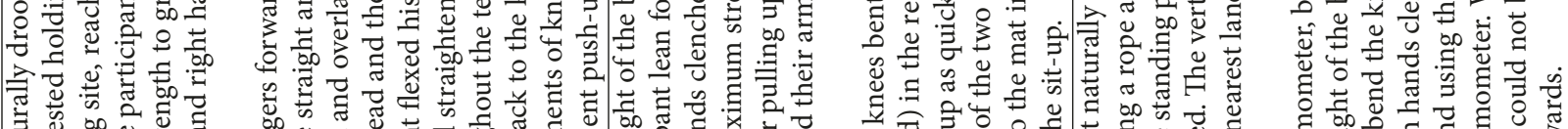

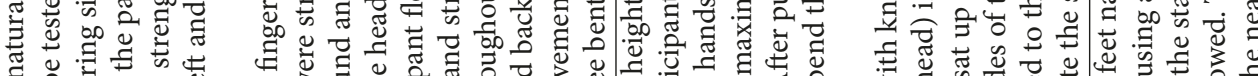

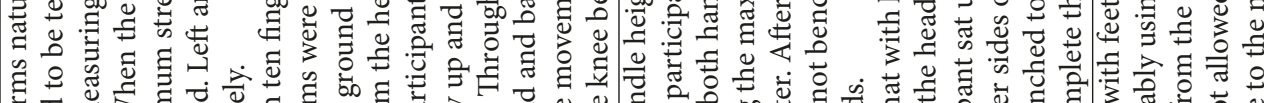

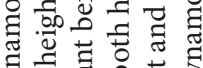

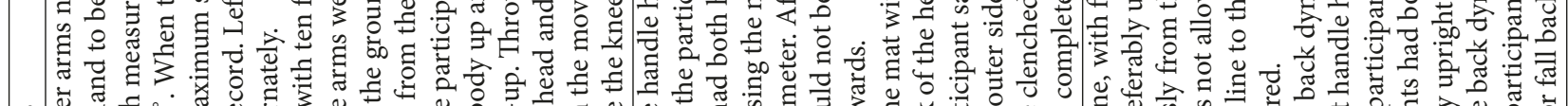

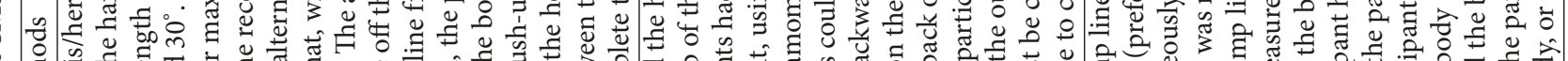

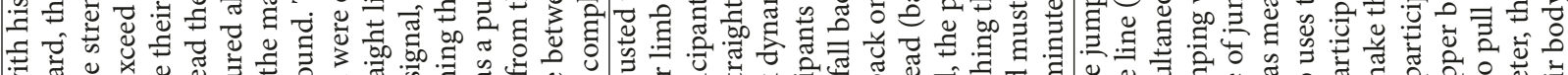

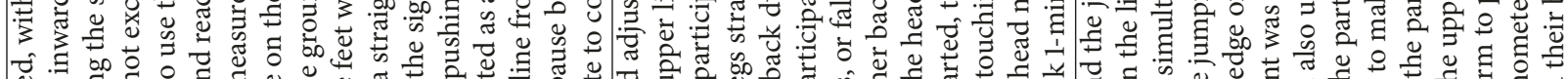

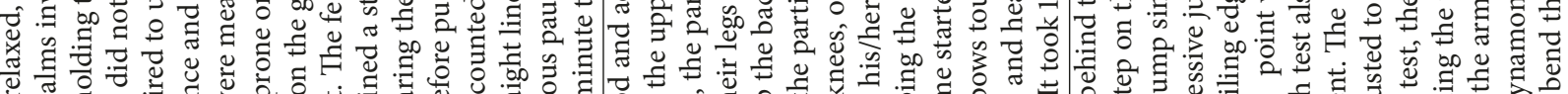

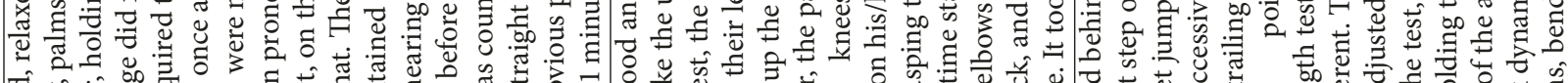

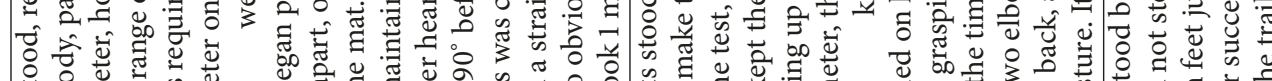

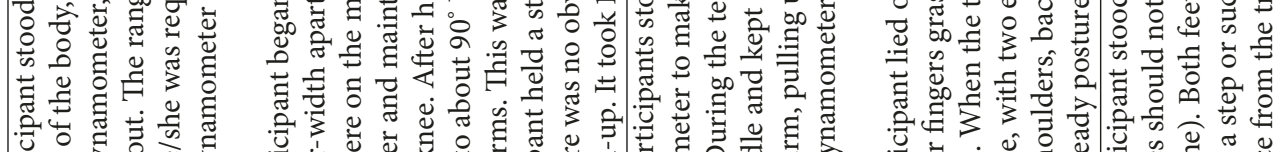

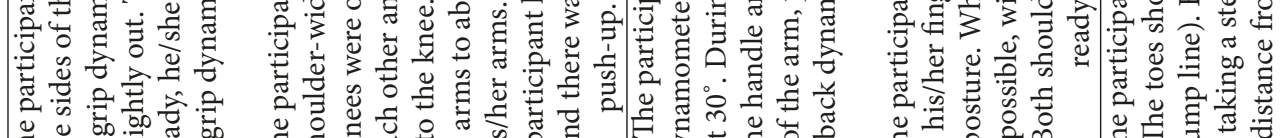

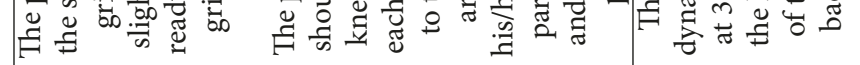

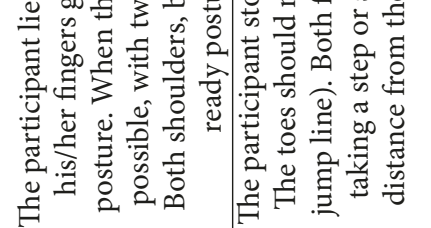
क्षे

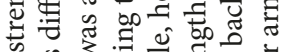

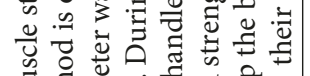

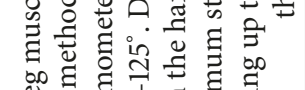

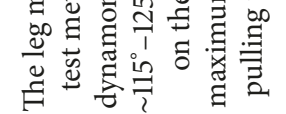

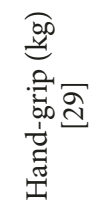

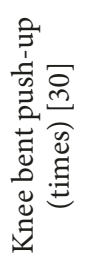

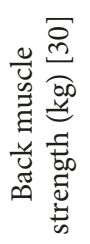


TABLE 2: The anthropometry characteristics of participants.

\begin{tabular}{|c|c|c|c|c|}
\hline & UB & $\mathrm{RB}$ & UG & RG \\
\hline Height $(\mathrm{cm})$ & $144.64 \pm 4.81^{\Delta \hat{r}}$ & $140.2 \pm 4.05$ & $142.17 \pm 9.55^{\text {约 }}$ & $139.93 \pm 6.78$ \\
\hline Weight $(\mathrm{kg})$ & $40.67 \pm 7.41^{\Delta \hat{4}}$ & $35.2 \pm 8.02$ & $35.98 \pm 9.73$ & $33.16 \pm 6.07$ \\
\hline Vital capacity $(\mathrm{ml})$ & $1750 \pm 296.24^{\text {约 }}$ & $1695.9 \pm 273.15$ & 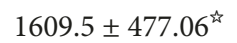 & $1669 \pm 307.01$ \\
\hline
\end{tabular}

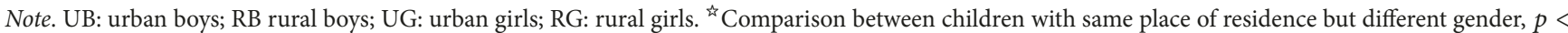
0.05. ${ }^{\triangle}$ Comparison between children of same gender but different place of residence, $p<0.05$.

TABLE 3: The results of SMST.

\begin{tabular}{|c|c|c|c|c|}
\hline & UB & $\mathrm{RB}$ & UG & RG \\
\hline Hand-grip (kg) & $14.36 \pm 2.04^{\triangle \dot{r}}$ & $11.22 \pm 3.79^{\text {म }}$ & $12.75 \pm 4.10$ & $10.24 \pm 3.25$ \\
\hline Knee bent push-ups $(\mathrm{kg})$ & $16.32 \pm 3.27^{\triangle \text { 不的 }}$ & $14.57 \pm 3.78^{\Delta \text { 不能 }}$ & $11.16 \pm 3.49$ & $9.87 \pm 2.32$ \\
\hline Back muscle strength (kg) & $43.4 \pm 7.89^{\Delta \dot{x}}$ & $55.5 \pm 11.77^{\Delta \text { 不访 }}$ & $39.2 \pm 9.78$ & $42.8 \pm 8.13$ \\
\hline Sit-ups (times) & $32.14 \pm 8.22$ & $33.32 \pm 7.56$ & $32.76 \pm 7.87$ & $31.59 \pm 9.05$ \\
\hline Leg muscle strength $(\mathrm{kg})$ & $49.9 \pm 9.23^{\triangle \Delta}$ & $83.8 \pm 19.46^{\triangle \Delta \dot{r}}$ & $45.5 \pm 16.07^{\text {头 }}$ & $55.3 \pm 15.22$ \\
\hline Standing long jump (m) & $1.67 \pm 0.45$ & $1.72 \pm 0.23^{\text {负的 }}$ & $1.53 \pm 0.34$ & $1.46 \pm 0.49$ \\
\hline
\end{tabular}

Note. UB: urban boys; RB rural boys; UG: urban girls; RG: rural girls. ${ }^{2}$ Comparison between children with same place of residence but different gender, $p<$ 0.05 , 初 $p<0.01 .{ }^{\triangle}$ Comparison between children of same gender but different place of residence, $p<0.05,{ }^{\Delta} p<0.01$.

cumulative contribution rate of extracted common factor was over $80 \%$, this factor could explain most of the information [27]. We then extracted the public factors by conducting a factor analysis and calculated the total factor score $\left(F_{\text {total }}\right)$ according to the public factor contribution rate.

2.3.2. Data Analysis. To study the validity of the SMST indicators, Pearson correlation analyses were used to analyze the correlation of the SMST indicators and the $F_{\text {total }}$. Twoway analysis of variance (residence * gender) was used to investigate the differences in the indicators of SMST. All statistical analyses were performed using the Statistical Package for Social Sciences (SPSS, v.16.0; SPSS Inc., Chicago), and the level of significance was set at 0.05 .

\section{Results}

3.1. Participant Anthropometry. As shown in Table 2, the height of urban students was significantly higher than that of rural students $(p<0.05)$, especially among girls $(p<0.05)$. In terms of weight, urban students were significantly heavier than rural students $(p<0.05)$. In terms of vital capacity, boys had significantly higher scores than girls $(p<0.05)$, but the difference was not significant across place of residence.

3.2. Simple Muscle Strength Test. As shown in Table 3, the upper limbs of urban students scored significantly higher than rural students $(p<0.05)$. Boys scored significantly higher in the kneeling push-up than girls $(p<0.01)$. In addition, urban children scored significantly higher in the kneeling push-up than rural children $(p<0.05)$. Back muscle strength was greater in the male than in the female participants $(p<0.01)$; rural children had greater back muscle strength than urban children (all $p<0.01$ ). Specifically, rural boys scored higher in the back muscle strength test than urban girls. There was no significant difference in sit-up across gender and place of residence. Boys had significantly greater leg muscle strength than girls $(p<0.01)$ while rural participants scored higher in leg muscle strength test than urban participants, especially among boys $(p<0.01)$. Boys scored higher in the standing long jump than girls, with rural boys scoring the highest and urban girls the lowest. There was no difference in the standing long jump between urban and rural children.

\subsection{Isokinetic Strength Test}

3.3.1. Peak Torque of Six Joints. The results of IST are presented in Table 4. Compared with the right shoulder, the $90^{\circ} / \mathrm{s}, 180^{\circ} / \mathrm{s}$, and $240 \% \mathrm{~s}$ PT of the left shoulder flexor were significantly lower (all $p<0.01$ ). Compared with the right hip, the extended $180^{\circ} / \mathrm{s}$ PT and flexor $90^{\circ} / \mathrm{s}$ and $180^{\circ} / \mathrm{s}$ PT of left hip were significantly higher (all $p<0.01$ ). The $240^{\circ} / \mathrm{s} \mathrm{PT}$ of left hip flexor was significantly higher than that of the right hip $(p<0.05)$.

Compared with the right knee, the $90^{\circ} / \mathrm{s}$ PT $(p<0.01)$ and $180^{\circ} / \mathrm{s}$ PT $(p<0.05)$ of left knee flexor were significantly lower. Compared with the right ankle, the $90^{\circ} / \mathrm{s}, 180^{\circ} / \mathrm{s}$, and $240^{\circ} / \mathrm{s}$ PT of left ankle extensor were significantly higher (all $p<0.01)$ while the $90^{\circ} / \mathrm{s} \mathrm{PT}(p<0.01)$ and $180^{\circ} / \mathrm{s} \mathrm{PT}(p<$ $0.05)$ of left ankle flexor were significantly lower. For the other joints, the PTs of right side were higher than the left side, but the differences were not significant $(p>0.05)$.

3.3.2. Unit Weight Torques of Six Joints. The results of unit weight torque (UWT) are similar to those of PT (Table 5). Compared with the right shoulder, the $90^{\circ} / \mathrm{s}, 180^{\circ} / \mathrm{s}$, and $240^{\circ} / \mathrm{s}$ UWT of left shoulder flexor were significantly lower (all $p<0.01$ ). Specifically, the $180^{\circ} / \mathrm{s}, 240^{\circ} / \mathrm{s}$, and $90^{\circ} / \mathrm{s}$ UWT of extensors and $90^{\circ} / \mathrm{s}$ UWT of flexors under working conditions were significantly different; the left shoulder is lower than the right shoulder (all $p<0.01$ ). There were also differences in $90 \%$ UWT of extensor and $180^{\circ} \%$ and $240^{\circ} / \mathrm{s}$ UWT of flexor between left and right shoulders: left 
TABLE 4: The peak torques of six joints.

\begin{tabular}{|c|c|c|c|c|c|c|}
\hline & \multicolumn{3}{|c|}{ Extensor PT } & \multicolumn{3}{|c|}{ Flexor PT } \\
\hline & $90^{\circ} / \mathrm{S}$ & $180^{\circ} / \mathrm{s}$ & $240^{\circ} / \mathrm{s}$ & $90^{\circ} / \mathrm{S}$ & $180^{\circ} / \mathrm{s}$ & $240^{\circ} / \mathrm{s}$ \\
\hline Left shoulder & $12.97 \pm 5.08$ & $8.78 \pm 4.95$ & $5.54 \pm 4.44$ & $12.02 \pm 4.33^{* *}$ & $6.76 \pm 6.25^{* *}$ & $1.82 \pm 4.6^{* *}$ \\
\hline Right shoulder & $14.51 \pm 6.25$ & $10.61 \pm 5.95$ & $8.01 \pm 6.48$ & $14.39 \pm 6.81$ & $10.23 \pm 7.31$ & $5.11 \pm 6.53$ \\
\hline Left elbow & $7.33 \pm 3.30$ & $5.97 \pm 3.42$ & $4.56 \pm 2.73$ & $7.65 \pm 2.70$ & $5.13 \pm 2.76$ & $2.89 \pm 3.04$ \\
\hline Right elbow & $8.08 \pm 3.27$ & $5.76 \pm 2.81$ & $4.95 \pm 3.07$ & $9.28 \pm 2.86$ & $6.98 \pm 2.68$ & $4.97 \pm 3.21$ \\
\hline Left wrist & $2.56 \pm 1.60$ & $1.18 \pm 2.28$ & $0.41 \pm 1.08$ & $2.67 \pm 1.78$ & $1.82 \pm 1.84$ & $1.13 \pm 1.40$ \\
\hline Right wrist & $2.68 \pm 3.85$ & $1.02 \pm 1.33$ & $0.35 \pm 0.91$ & $3.16 \pm 1.88$ & $2.14 \pm 1.80$ & $1.91 \pm 1.77$ \\
\hline Left hip & $30.8 \pm 11.64$ & $26.8 \pm 12.32^{* *}$ & $19.9 \pm 13.11$ & $39.86 \pm 10.08^{* *}$ & $34.42 \pm 11.81^{* *}$ & $29.93 \pm 12.18^{*}$ \\
\hline Right hip & $26.0 \pm 10.76$ & $22.0 \pm 11.88$ & $16.0 \pm 10.67$ & $35.32 \pm 10.30$ & $28.41 \pm 10.46$ & $24.06 \pm 10.93$ \\
\hline Left knee & $46.1 \pm 12.29$ & $37.3 \pm 10.05$ & $32.39 \pm 9.23$ & $18.57 \pm 7.31^{* *}$ & $18.71 \pm 8.00^{*}$ & $16.62 \pm 7.47$ \\
\hline Right knee & $47.9 \pm 12.86$ & $39.1 \pm 10.76$ & $33.37 \pm 9.69$ & $23.01 \pm 7.40$ & $21.41 \pm 7.59$ & $18.16 \pm 6.35$ \\
\hline Left ankle & $23.76 \pm 6.54^{* *}$ & $21.00 \pm 5.23^{* *}$ & $19.15 \pm 5.47^{* *}$ & $3.12 \pm 2.58^{* *}$ & $0.96 \pm 1.19$ & $0.19 \pm 0.34^{* *}$ \\
\hline Right ankle & $8.38 \pm 3.01$ & $5.06 \pm 2.41$ & $1.11 \pm 2.25$ & $15.94 \pm 6.67$ & $1.94 \pm 6.16$ & $9.46 \pm 5.05$ \\
\hline
\end{tabular}

Note. ${ }^{*}$ Compared with the right joint, $p<0.05 ;{ }^{* *} p<0.01$.

TABLE 5: The unit weight torque of six joints.

\begin{tabular}{|c|c|c|c|c|c|c|}
\hline & \multicolumn{3}{|c|}{ Extensor UWT } & \multicolumn{3}{|c|}{ Flexor UWT } \\
\hline & $90^{\circ} / \mathrm{S}$ & $180^{\circ} / \mathrm{s}$ & $240^{\circ} / \mathrm{s}$ & $90^{\circ} / \mathrm{S}$ & $180^{\circ} / \mathrm{s}$ & $240^{\circ} / \mathrm{s}$ \\
\hline Left shoulder & $16.36 \pm 6.11^{*}$ & $11.12 \pm 6.44^{* *}$ & $6.97 \pm 5.35^{* *}$ & $12.03 \pm 4.34^{* *}$ & $8.77 \pm 9.51^{*}$ & $1.77 \pm 4.48^{*}$ \\
\hline Right shoulder & $19.46 \pm 12.39$ & $14.41 \pm 10.70$ & $10.02 \pm 8.40$ & $14.40 \pm 6.81$ & $14.89 \pm 19.30$ & $6.03 \pm 9.51$ \\
\hline Left elbow & $9.67 \pm 5.09$ & $7.50 \pm 5.24$ & $5.94 \pm 4.27$ & $9.86 \pm 4.31$ & $6.48 \pm 3.68$ & $3.42 \pm 3.71$ \\
\hline Right elbow & $10.36 \pm 4.34$ & $7.49 \pm 4.04$ & $6.20 \pm 3.96$ & $11.91 \pm 3.92$ & $8.81 \pm 3.68$ & $6.09 \pm 3.89$ \\
\hline Left wrist & $3.24 \pm 2.27$ & $1.37 \pm 2.41$ & $0.49 \pm 1.29$ & $3.23 \pm 2.01$ & $2.16 \pm 2.24$ & $1.39 \pm 1.81$ \\
\hline Right wrist & $2.98 \pm 1.88$ & $1.25 \pm 1.68$ & $0.38 \pm 1.05$ & $3.97 \pm 2.68$ & $2.72 \pm 2.53$ & $2.38 \pm 2.35$ \\
\hline Left hip & $66.65 \pm 43.16^{* *}$ & $65.36 \pm 108.39^{* *}$ & $52.21 \pm 94.52^{* *}$ & $82.65 \pm 45.67^{* *}$ & $69.37 \pm 43.41^{* *}$ & $58.09 \pm 38.17^{* *}$ \\
\hline Right hip & $33.63 \pm 18.86$ & $26.99 \pm 13.14$ & $19.82 \pm 12.48$ & $45.17 \pm 17.70$ & $36.46 \pm 16.83$ & $30.41 \pm 14.94$ \\
\hline Left knee & $61.41 \pm 26.40$ & $49.36 \pm 20.57$ & $42.85 \pm 18.31$ & $23.94 \pm 9.90^{*}$ & $23.95 \pm 10.42$ & $21.32 \pm 9.99$ \\
\hline Right knee & $58.61 \pm 15.6$ & $47.7 \pm 11.14$ & $40.59 \pm 10.9$ & $28.17 \pm 8.55$ & $25.40 \pm 7.28$ & $22.14 \pm 7.26$ \\
\hline Left ankle & $29.18 \pm 8.76^{* *}$ & $25.66 \pm 7.05^{* *}$ & $23.27 \pm 7.49^{* *}$ & $3.73 \pm 3.07^{* *}$ & $1.17 \pm 1.56^{* *}$ & $0.25 \pm 0.46^{* *}$ \\
\hline Right ankle & $11.62 \pm 11.94$ & $6.91 \pm 7.24$ & $1.82 \pm 6.20$ & $21.60 \pm 21.27$ & $15.78 \pm 14.56$ & $13.20 \pm 15.70$ \\
\hline
\end{tabular}

Note. ${ }^{*}$ Compared with the right joint, $p<0.05 ;{ }^{* *} p<0.01$.

were lower (all $p<0.05$ ). Compared with the right hip, the $90^{\circ} / \mathrm{s}, 180^{\circ} / \mathrm{s}$, and $240^{\circ} / \mathrm{s}$ UWT of left hip flexors were higher $(p<0.01)$.

Compared with the right knee, the $90^{\circ} / \mathrm{s}$ UWT of left knee flexor under working condition was significantly lower $(p<$ 0.05). Compared with the right ankle, the $90^{\circ} / \mathrm{s}, 180^{\circ} / \mathrm{s}$, and $240^{\circ} / \mathrm{s}$ UWT of left ankle extensor were significantly higher (all $p<0.01$ ). The $90^{\circ} / \mathrm{s}, 180^{\circ} / \mathrm{s}$, and $240^{\circ} / \mathrm{s}$ UWT of left ankle flexor of were significantly lower (all $p<0.01$ ). In total, the UWTs of other joints of the right side were higher than those of the left side, but the difference was not significant.

\subsection{Validity of SMST Indicators}

3.4.1. Correlations between Indicators of SMST. The correlation coefficients between indictors of SMST are presented in Table 6. Hand-grip strength was significantly correlated with back and leg muscle strength (all $p<0.05$ ); kneeling push-up was significantly related to hand-grip strength and back and leg muscle strength (all $p<0.05$ ); back muscle strength was significantly correlated with leg muscle strength $(p<0.05)$. Meanwhile, the correlations between sit-ups and the standing long jump with the remaining indicators of SMST were not significant $(p>0.05)$. (Table 6).

3.4.2. Criterion-Related Validity of SMST Indicators to Access Whole Body Muscle Strength. The KMO and Bartlett test results showed that all correlation coefficients between each indicator of IST were greater than 0.3 for UB, UG, rural boys, and RG. The KMO test results for UB, UG, RB, and RG were, respectively, 0.876, 0.833, 0.856, and 0.872. Bartlett's sphericity test showed that the data was suitable for factor analysis $(p<0.001)$. According to the principle of factor analysis, when the cumulative contribution rate of extracted common factor was over $80 \%$, this factor can explain most of the information (Figure 1) [31].

There were seven common factors for urban boys (Table 7 ), with the cumulative contribution rate of $83.67 \%$. 
TABLE 6: Correlation between indicators of SMST.

\begin{tabular}{lcccccc}
\hline & Hand-grip & Knee bent push-up & Back muscle strength & Sit-ups & Leg muscle strength & Standing long jump \\
\hline Hand-grip & 1 & & $0.596^{* *}$ & $0.234^{* *}$ & $0.504^{* *}$ & $0.398^{* *}$ \\
Knee bent push-up & $0.766^{* *}$ & 1 & $0.607^{* *}$ & $0.423^{* *}$ & $0.504^{* *}$ & $0.398^{* *}$ \\
Back muscle strength & $0.596^{* *}$ & & 1 & 0.378 & $0.725^{* *}$ & 0.096 \\
Sit-ups & $0.234^{* *}$ & & 0.378 & 1 & $0.463^{*}$ & $0.367^{*}$ \\
Leg muscle strength & $0.504^{* *}$ & & $0.725^{* *}$ & $0.463^{*}$ & 1 & 0.151 \\
Standing long jump & $0.398^{* *}$ & & 0.096 & $0.367^{*}$ & 0.151 & 1 \\
\hline
\end{tabular}

${ }^{*} p<0.05$ (two-tailed); ${ }^{* *} p<0.01$ (two-tailed).

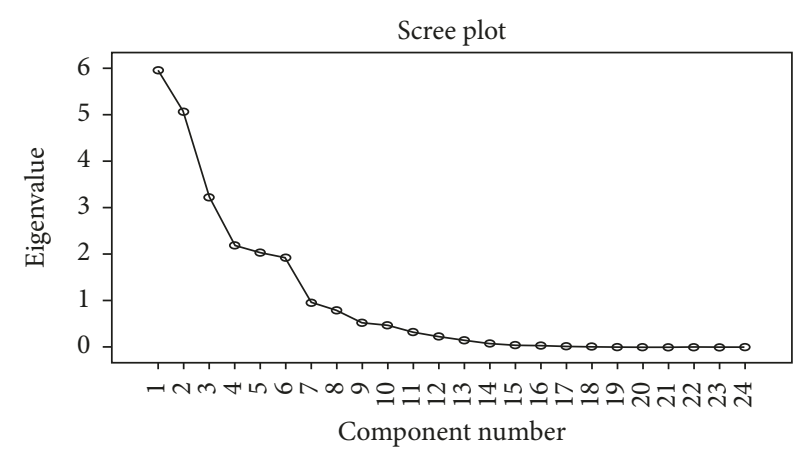

(a)

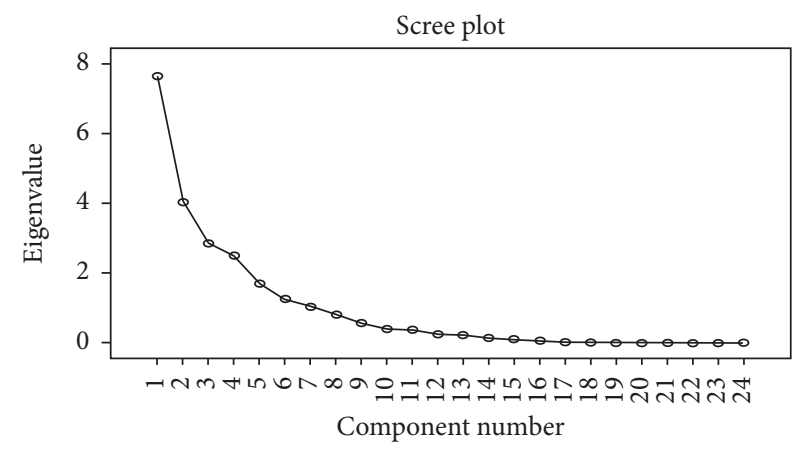

(c)

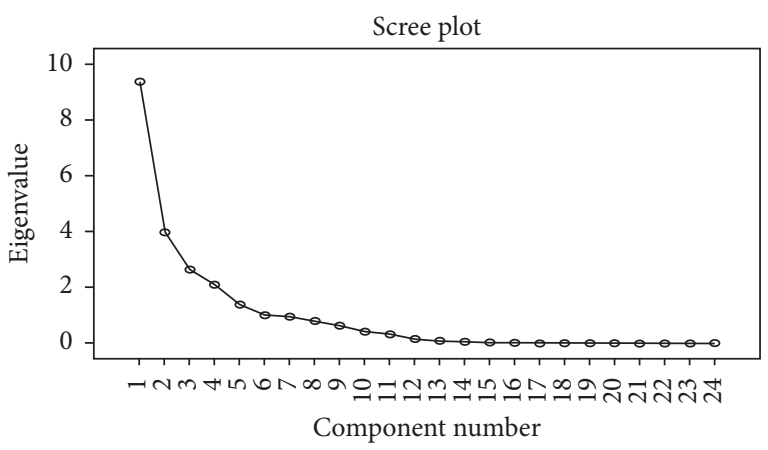

(b)

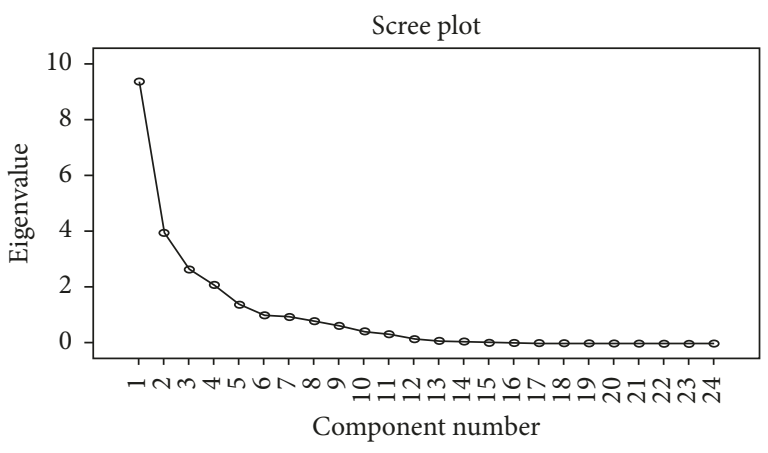

(d)

FIGURE 1: Common factor and feature scatter plot. (a) Urban boys, common factors = 7; (b) urban girls, common factors =6; (c) rural boys, common factors $=5$; $(\mathrm{d})$ rural girls, common factors $=5$.

There were six common factors for urban girls (Table 8), with a cumulative contribution rate of $80.64 \%$. There were five common factors for rural boys (Table 9), with a cumulative contribution rate of $83.26 \%$. For rural girls, there were five common factors (Table 10), with a cumulative contribution rate of $81.46 \%$. The total score $\left(F_{\text {total }}\right)$ was calculated according to the contribution rate of each common factor.

The correlation coefficients were shown in Table 11. For $\mathrm{UG}$, the correlation coefficient between $F_{\text {total }}$ and back muscle strength was the highest $(r=0.803, p<0.01)$, while the correlation coefficients between $F_{\text {total }}$ and leg muscle strength were the highest among UB $(r=0.811, p<0.01), \mathrm{RB}(r$ $=0.837, p<0.01)$, and RG $(r=0.801, p<0.01)$, followed by the correlation coefficients between $F_{\text {total }}$ and back muscle strength (urban boys: $r=0.774$, rural boys: $r=0.824$; rural girls: $r=0.799$, all $p<0.01$ ). The correlation coefficients between $F_{\text {total }}$ and hand-grip were the lowest among UB ( $r$
$=0.611, p<0.01), \mathrm{RB}(r=0.635, p<0.01)$, and RG $(r=0.548$, $p<0.01)$.

\section{Discussion}

The main purpose of this study was to determine the criterion-related validity of the SMST indicators for handgrip strength, knee bent pull-up, back muscle strength, leg muscle strength, standing long jump, and sit-up to assess whole body muscle strength in Chinese children aged 10 to 12 years. Gender and residence were included as betweensubject factors because earlier studies have shown differences in the concurrent validity between males and females and urban and rural populations in muscle strength [32,33]

The results showed that the criterion-related validity of SMST indicators to assess whole body muscle strength was moderate to high. The correlation SMST and $F_{\text {total }}$ ranged 
TABLE 7: Factor analysis of IST among urban boys.

\begin{tabular}{|c|c|c|c|c|c|c|}
\hline$x_{1}$ & $x_{2}$ & $x_{3}$ & $x_{4}$ & $x_{5}$ & $x_{6}$ & $x_{7}$ \\
\hline .716 & -.032 & .020 & -.227 & .199 & -.484 & .202 \\
\hline .692 & .078 & .127 & -.193 & .164 & -.562 & .260 \\
\hline .761 & -.426 & .023 & -.086 & .028 & .221 & .010 \\
\hline .678 & -.458 & -.070 & .005 & -.101 & .111 & -.091 \\
\hline .676 & -.246 & -.021 & .493 & .342 & .002 & -.115 \\
\hline .716 & -.446 & .052 & .235 & .389 & .038 & -.018 \\
\hline .326 & .513 & -.476 & -.400 & .131 & .393 & .142 \\
\hline .450 & .567 & -.437 & -.300 & -.032 & .323 & .157 \\
\hline-.052 & -.462 & -.083 & .204 & .114 & .303 & .072 \\
\hline .649 & -.200 & -.518 & .214 & .346 & -.036 & -.122 \\
\hline .432 & -.648 & .087 & -.013 & -.075 & .003 & .487 \\
\hline .570 & -.263 & .171 & -.320 & -.283 & .466 & .194 \\
\hline .081 & .510 & .729 & .104 & .119 & .193 & .178 \\
\hline .102 & .356 & .731 & .364 & .001 & .059 & .339 \\
\hline .069 & .479 & .207 & -.001 & .446 & .116 & -.445 \\
\hline .230 & .728 & .202 & .204 & .306 & .076 & .133 \\
\hline .528 & .133 & .279 & -.600 & -.017 & -.119 & -.311 \\
\hline .728 & .088 & .320 & -.348 & -.017 & .008 & -.393 \\
\hline .701 & .500 & -.313 & .083 & -.069 & -.084 & .156 \\
\hline .730 & .474 & -.012 & .028 & -.309 & .041 & .025 \\
\hline .446 & -.303 & .417 & .253 & -.097 & .394 & -.197 \\
\hline .460 & -.091 & .223 & .008 & -.667 & -.247 & -.206 \\
\hline .301 & .406 & -.374 & .540 & -.376 & .035 & -.041 \\
\hline .470 & .316 & -.144 & .640 & -.265 & -.152 & -.142 \\
\hline
\end{tabular}

Urban Boy Group. $F_{\text {total }}=0.8611 \times 1+0.6455 \times 2+0.5112 \times 3+0.3843 \times 4+0.1633 \times 5+0.0854 x 6+0.0799 \times 7$.

TABLE 8: Factor analysis of IST among urban girls.

\begin{tabular}{|c|c|c|c|c|c|}
\hline$x_{1}$ & $x_{2}$ & $x_{3}$ & $x_{4}$ & $x_{5}$ & $x_{6}$ \\
\hline .894 & -.029 & .046 & .013 & .180 & -.255 \\
\hline .870 & -.116 & -.034 & -.256 & .089 & -.196 \\
\hline .613 & -.293 & -.628 & .065 & -.134 & .093 \\
\hline .410 & .085 & -.363 & -.580 & .024 & .162 \\
\hline .150 & .766 & -.017 & .142 & .327 & .273 \\
\hline .081 & .637 & .404 & -.353 & .321 & .175 \\
\hline .897 & -.056 & -.158 & .042 & .084 & .101 \\
\hline .767 & .363 & -.173 & -.232 & .167 & -.107 \\
\hline .745 & .141 & 199 & -.380 & -.046 & .097 \\
\hline .325 & .662 & .242 & -.053 & -.222 & .185 \\
\hline .668 & -.375 & -.111 & .544 & .108 & -.031 \\
\hline .666 & -.435 & .142 & .175 & .139 & .363 \\
\hline-.089 & .708 & .239 & .205 & -.154 & -.166 \\
\hline .494 & .316 & .225 & .095 & -.418 & -.042 \\
\hline-.064 & .436 & -.600 & .435 & .167 & .000 \\
\hline-.214 & .317 & -.420 & .295 & .624 & -.109 \\
\hline-.055 & -.083 & .861 & .046 & .151 & -.316 \\
\hline-.059 & -.211 & .710 & -.309 & .445 & .000 \\
\hline .822 & -.332 & .135 & -.064 & .035 & .083 \\
\hline .817 & .010 & -.019 & .126 & -.018 & -.326 \\
\hline-.200 & -.387 & .115 & -.010 & .002 & .791 \\
\hline-.056 & -.569 & .494 & .371 & .233 & -.107 \\
\hline .421 & .335 & .346 & .539 & .175 & .339 \\
\hline .412 & .238 & .485 & .398 & -.497 & .076 \\
\hline
\end{tabular}

Urban Girl Group. $F_{\text {total }}=0.7748 \times 1+0.6637 \times 2+0.534 \times 3+0.1778 x 4+0.098 \times 5+0.087 x 6$. 
TABLE 9: Factor analysis of IST among rural boys.

\begin{tabular}{|c|c|c|c|c|}
\hline$x_{1}$ & $x_{2}$ & $x_{3}$ & $x_{4}$ & $x_{5}$ \\
\hline .769 & -.247 & .005 & .317 & -.175 \\
\hline .792 & -.224 & -.198 & .418 & -.257 \\
\hline-.219 & .746 & -.072 & .245 & -.118 \\
\hline .870 & -.094 & -.206 & .073 & -.368 \\
\hline .389 & .712 & -.189 & -.009 & -.164 \\
\hline .400 & .786 & -.242 & -.308 & -.092 \\
\hline .340 & .641 & -.097 & .660 & .042 \\
\hline .753 & .441 & -.061 & .230 & .097 \\
\hline .711 & .039 & .095 & .049 & .150 \\
\hline .688 & .289 & -.391 & -.181 & .199 \\
\hline-.553 & .338 & .093 & -.015 & .512 \\
\hline-.444 & .515 & -.465 & -.237 & -.014 \\
\hline .895 & -.036 & -.062 & -.127 & -.089 \\
\hline .769 & .064 & -.293 & -.290 & .115 \\
\hline .946 & -.179 & .032 & .047 & -.084 \\
\hline .906 & -.217 & .022 & .025 & .096 \\
\hline .870 & -.112 & -.104 & .002 & -.030 \\
\hline .856 & -.113 & .210 & -.317 & .090 \\
\hline .516 & .372 & .627 & -.240 & -.005 \\
\hline .785 & .028 & -.004 & -.279 & .299 \\
\hline .252 & .278 & .897 & .024 & -.099 \\
\hline .288 & .306 & .889 & -.005 & -.090 \\
\hline .859 & -.162 & -.071 & -.198 & .248 \\
\hline .319 & -.096 & .042 & .523 & .684 \\
\hline
\end{tabular}

Rural Boy Group. $F_{\text {total }}=0.8327 \times 1+0.731 \times 2+0.4425 \times 3+0.1387 \times 4+0.0944 \times 5$.

from 0.425 to 0.811 . In addition, leg muscle strength and back muscle strength demonstrated the highest validity scores, $r=0.811$ and 0.80 , respectively; sit-ups, hand-grip, and standing long jump demonstrated the lowest validity scores, $r=0.425,0.455$, and 0.465 , respectively. In the upper body, knee bent push-up demonstrated greater validity than handgrip strength; in the trunk, back muscle strength is more valid than sit-ups; in the lower body, leg muscle strength is more valid than the standing long jump.

Similar results were found in several other studies. For instance, in Japan, back, hand-grip, wrist, leg, and abdominal muscle strength were adopted as indicators [34]. The validity of the indicators was examined using the mean and standard deviation of each test indicator as the standard of comparison. The results showed that the correlation coefficient between back muscle strength and the standard of comparison $(r=$ 0.9172) was higher than hand-grip and leg strength. Prior research has examined the validity of indicators of the upper limb strength quality tests. The research has examined the convergent validity of push-ups, pull-ups, hand-grip, and the inverted row. They found that the convergent validity of the push-up was the highest among all indicators while the rest of the indicators were not sufficiently valid. The results showed that hand-grip strength was a validity indicator $[35,36]$. However, some studies also found that the hand-grip test was not valid [37], especially in accessing whole body muscle strength. Previous studies suggested that the knee bent pushup was a valid indicator of upper limb strength quality test $[38,39]$. Researchers used the 1 repetition maximum (1RM) leg extension test to assess the validity for lower-body muscular power and found that the standing long jump test can be a useful tool to assess lower-body muscular strength in children, but not whole body muscle strength [40]. Children between the ages of 6 and 17 were tested [41]. The lower limb strength test included standing long jump, vertical jump, squat jump, and the countermovement jump. Using a multivariate regression analysis, this study analyzed the relationship between indicators of upper limb strength tests. In assessing whole body muscle strength, Tillin et al. [42] recommended multijoint rather than single joint testing due to the specific neural and mechanical conditions in athletic performance tasks, such as sprinting and jumping. The results showed that the correlation coefficients between the standing long jump and other indicators of upper limb strength tests were low [43]. However, the standing long jump has also been challenged by researchers because the test results were susceptible to factors, such as skill learning. This indicated that back muscle strength and leg muscle strength may give the highest validity of assessment for whole body muscle strength.

The present study also sought to compare the validity of SMST indicators to assess whole body muscle strength in 
TABLE 10: Factor analysis of IST among rural girls.

\begin{tabular}{|c|c|c|c|c|c|}
\hline$x_{1}$ & $x_{2}$ & $x_{3}$ & $x_{4}$ & $x_{5}$ & $x_{6}$ \\
\hline .688 & .352 & -.083 & .096 & -.301 & -.105 \\
\hline .733 & .352 & .104 & -.176 & .087 & -.411 \\
\hline .856 & -.167 & -.204 & .208 & .006 & -.123 \\
\hline .709 & -.405 & -.357 & -.210 & -.085 & .019 \\
\hline .479 & -.478 & -.376 & -.468 & -.025 & .254 \\
\hline .721 & .101 & -.470 & .200 & .318 & -.100 \\
\hline .562 & .302 & -.362 & .543 & -.259 & -.054 \\
\hline .530 & .365 & .566 & -.072 & -.109 & .410 \\
\hline .545 & .574 & .130 & -.027 & .253 & .204 \\
\hline-.043 & .528 & .660 & .227 & -.017 & -.173 \\
\hline-.039 & .145 & .182 & .358 & .799 & .283 \\
\hline .445 & -.638 & .352 & .448 & .033 & -.124 \\
\hline .464 & -.662 & .260 & .479 & -.028 & -.092 \\
\hline .877 & -.369 & -.011 & .015 & .002 & -.096 \\
\hline .919 & -.239 & -.094 & .040 & -.017 & .079 \\
\hline .767 & .142 & -.093 & .267 & -.132 & .050 \\
\hline .853 & .282 & .085 & -.019 & .203 & -.097 \\
\hline .476 & -.442 & .662 & -.246 & -.124 & -.070 \\
\hline .664 & -.374 & .577 & -.255 & -.021 & -.007 \\
\hline .802 & .388 & .147 & -.092 & -.079 & .054 \\
\hline .623 & .237 & .052 & -.517 & -.025 & .047 \\
\hline .634 & -.269 & -.143 & -.157 & .559 & .179 \\
\hline .374 & .072 & -.051 & .299 & -.427 & .671 \\
\hline .672 & .547 & -.187 & -.154 & -.037 & -.187 \\
\hline
\end{tabular}

Rural Girl Group. $F_{\text {total }}=0.7133 \times 1+0.6207 \times 2+0.3345 \times 3+0.1159 \times 4+0.0709 \times 5$.

TABLE 11: Results of the correlation analyses of SMST indicators and $F_{\text {total }}$.

\begin{tabular}{lccccccccccc}
\hline & \multicolumn{2}{c}{ AC } & \multicolumn{2}{c}{ UB } & \multicolumn{3}{c}{ UG } & \multicolumn{2}{c}{ RB } & \multicolumn{2}{c}{ RG } \\
& $r$ & $p$ & $r$ & $p$ & $r$ & $p$ & $r$ & $p$ \\
\hline Hand-grip & 0.455 & $<0.01$ & 0.411 & $<0.01$ & 0.507 & $<0.01$ & 0.435 & $<0.01$ & 0.389 \\
Knee bent push-ups & 0.608 & $<0.01$ & 0.678 & $<0.01$ & 0.691 & $<0.01$ & 0.522 & $<0.01$ & 0.539 & $<0.01$ \\
Back muscle strength & 0.80 & $<0.01$ & 0.774 & $<0.01$ & 0.803 & $<0.01$ & 0.824 & $<0.01$ & 0.799 & $<0.01$ \\
Leg muscle strength & 0.811 & $<0.01$ & 0.811 & $<0.01$ & 0.789 & $<0.01$ & 0.837 & $<0.01$ & 0.801 & $<0.01$ \\
Standing long jump & 0.465 & $<0.01$ & 0.438 & $<0.01$ & 0.367 & $<0.01$ & 0.567 & $<0.01$ & 0.478 & $<0.01$ \\
Sit-ups & 0.425 & $<0.01$ & 0.345 & $<0.01$ & 0.428 & $<0.01$ & 0.389 & $<0.01$ & 0.516 & $<0.01$ \\
\hline
\end{tabular}

Note. AC: all children; UB: urban boys; RB: rural boys; UG: urban girls; RG: rural girls.

different genders and residences. The results for back muscle strength demonstrated the highest validity scores for UB, RB, and RG, $r=0.811,0.837$, and 0.801 , respectively, and leg muscle strength demonstrated the highest validity scores for UG, $r=$ 0.803. Leg muscle strength demonstrated the highest validity for males, but this is only the case for back muscle strength for females. Back muscle strength and leg muscle strength have higher validity in both the urban and rural children. For urban children, the knee bent push-up also has a high validity indicator but has poor validity for rural children.

There were differences in anthropometric characteristics between urban and rural children, and also differences in the SMST results. The evaluation of physical quality fitness tests for students has been concentrated on the adaptability of the test among children of different ages and genders around the world. Generally speaking, there were three kinds of situations in terms of the difference of indicators across age and gender. First, the indicators of test for junior students were same across gender, while the indicator for senior students was different from that of junior students, and there were differences in indicators between male and female senior students. For instance, in the School Physical Fitness Rewards Program of Hong Kong [44], general handgrip strength was the indicator of muscle strength of upper limb for primary school students. Push-ups and modified push-ups were the indicators of muscle strength of the upper limbs for male and female middle school students. Second, the indicator of senior students' genders was the same as 
that of junior students, while the indicator of senior students of the other genders was modified. For example, in the National Physical Fitness Award Program of Singapore [45], the indicator of muscle strength of the upper limbs was the modified pull-up for both males and females younger than 15 years. For those older than 15 years, the indicator for female students remained the modified pull-up while that of male students was the pull-up. Third, the indicator was different between male and female junior students. In addition, the indicator has also changed for senior students. For instance, the national education standards of the course "Sports" in Russia [46-48] stated that the indicator for girls aged 7 to 15 years was the overhanging arm flexion and extension, while that for girls aged 16 to 17 years was bicep curl to pull-up.

\section{Conclusion}

Back muscle strength and leg muscle strength can give the highest validity for assessing whole body muscle strength and also have higher validity in both urban and rural children. For urban children, the knee bent push-up also has a high validity indicator but poor validity for rural children.

In the future, back muscle strength and leg muscle strength can be considered as strength test indicators for Chinese student's physical fitness test. Meanwhile, residential differences in SMST indicators should be considered when setting up the physical fitness test evaluation indicators of students, especially for knee bent push-up.

\section{Conflicts of Interest}

The authors have no conflicts of interest to disclose in relation to the current research.

\section{Authors' Contributions}

During the construction of this study, Liqin Yin played a role in data collection, sorting, analysis, and writing the article. Changfa Tang played a role in developing the idea, overseeing data collection and analysis, and helping to edit the article. Xia Tao played a role in data collection, testing, and analysis.

\section{Acknowledgments}

The authors gratefully acknowledge the financial support from the national social science foundation of China (no. BLA090074). Liqin Yin would like to thank the coauthors for their generous support in conducting this study.

\section{References}

[1] C. S. Stump, E. J. Henriksen, Y. Wei, and J. R. Sowers, "The metabolic syndrome: role of skeletal muscle metabolism," Annals of Medicine, vol. 38, no. 6, pp. 389-402, 2006.

[2] R. R. Wolfe, "The underappreciated role of muscle in health and disease," American Journal of Clinical Nutrition, vol. 84, no. 3, pp. 475-482, 2006.

[3] R. S. Hutton and S. W. Atwater, "Acute and Chronic Adaptations of Muscle Proprioceptors in Response to Increased Use," Sports
Medicine: Evaluations of Research in Exercise Science and Sports Medicine, vol. 14, no. 6, pp. 406-421, 1992.

[4] B. Ferguson, "ASCM'S Guidelines for Exercise Testing and Prescription (ninth edition)," Journal of the Canadian Chiropractic Association, vol. 58, no. 3, pp. 328-328, 2014.

[5] H. B. Fan, Y. P. Sun, and L. Ji, "Age and gender universality research on different upper limbs strength indicatiors in physical fitness test based surface electromyography muscular contribution," China Sport Science and Technology, vol. 52, no. 5, pp. 83-97, 2016.

[6] B. Saint Romain and M. T. Mahar, "Norm-referenced and criterion-referenced reliability of the push-up and modified pull-up," Measurement in Physical Education and Exercise Science, vol. 5, no. 2, pp. 67-80, 2001.

[7] C. Boyer, M. Tremblay, T. J. Saunders et al., "Feasibility, validity, and reliability of the plank isometric hold as a field-based assessment of torso muscular endurance for children 8-12 years of age," Pediatric exercise science, vol. 25, no. 3, pp. 407-422, 2013.

[8] G. Markovic, D. Dizdar, I. Jukic, and M. Cardinale, "Reliability and factorial validity of squat and countermovement jump tests," The Journal of Strength and Conditioning Research, vol. 18, no. 3, pp. 551-555, 2004.

[9] H. M. Wood and T. A. Baumgartner, "Objectivity, reliability, and validity of the bent-knee push-up for college-age women," Measurement in Physical Education and Exercise Science, vol. 8, no. 4, pp. 203-212, 2004.

[10] J. Castropiñero, E. G. Artero, V. Españaromero et al., "Criterionrelated validity of field-based fitness tests in youth: A systematic review," British Journal of Sports Medicine, vol. 44, no. 13, pp. 934-943, 2010.

[11] M. V. Garnacho-Castaño, S. López-Lastra, and J. 1. MatéMuñoz, "Reliability and validity assessment of a linear position transducer," Journal of Sports Science \& Medicine, vol. 14, no. 1, pp. 128-136, 2015.

[12] C. T. M. Davies, M. J. White, and K. Young, "Electrically evoked and voluntary maximal isometric tension in relation to dynamic muscle performance in elderly male subjects, aged 69 years," European Journal of Applied Physiology, vol. 51, no. 1, pp. 37-43, 1983.

[13] D. T. McMaster, N. Gill, J. Cronin, and M. McGuigan, "A brief review of strength and ballistic assessment methodologies in sport," Sports Medicine, vol. 44, no. 5, pp. 603-623, 2014.

[14] R. R. Pate, M. L. Burgess, J. A. Woods, J. G. Ross, and T. Baumgartner, "Validity of field tests of upper body muscular strength," Research Quarterly for Exercise and Sport, vol. 64, no. 1, pp. 17-24, 1993.

[15] X. Aguado, M. Izquierdo, and J. L. Montesinos, "Kinematic and kinetic factors related to the standing long jump performance," J Human Move Studies, vol. 32, no. 4, pp. 157-169, 1997.

[16] F. Hongbin, S. Youpin, and J. Liu, "Enlightenment and international comparison of evaluation indicators and test methods of strength in physical fitness tests," China Sport Science, vol. 35, no. 1, pp. 80-87, 2015.

[17] G. Gang, Research on optimization of young students physical health evaluation in in xinjiang, for example [Ph.D. thesis], East China Normal University, 2014.

[18] H. B. Fan, Optimization Research on Measurement and Evaluation System of strength quality of ShangHai 6-14 Years old Students [Ph.D. thesis], East China Normal University, 2017. 
[19] R. C. T. Li, "Eccentric and concentric isokinetic knee flexion and extension: A reliability study using the Cybex 6000 dynamometer," British Journal of Sports Medicine, vol. 30, no. 2, pp. 156-160, 1996.

[20] M. J. Callaghan, C. J. McCarthy, A. Al-Omar, and J. A. Oldham, "The reproducibility of multi-joint isokinetic and isometric assessments in a healthy and patient population," Clinical Biomechanics, vol. 15, no. 9, pp. 678-683, 2000.

[21] C. A. Emery, M. E. Maitland, and W. H. Meeuwisse, "Test-retest reliability of isokinetic hip adductor and flexor muscle strength," Clinical Journal of Sport Medicine, vol. 9, no. 2, pp. 79-85, 1999.

[22] M. Julia, A. Dupeyron, I. Laffont et al., "Reproducibility of isokinetic peak torque assessments of the hip flexor and extensor muscles," Annals of Physical and Rehabilitation Medicine, vol. 53, no. 5, pp. 293-305, 2010.

[23] E. Aydoğ, S. T. Aydoğ, A. Çakci, and M. N. Doral, "Reliability of isokinetic ankle inversion- and eversion-strength measurement in neutral foot position, using the Biodex dynamometer," Knee Surgery, Sports Traumatology, Arthroscopy, vol. 12, no. 5, pp. 478-481, 2004.

[24] J. Van Meeteren, M. E. Roebroeck, and H. J. Stam, “Test-retest reliability in isokinetic muscle strength measurements of the shoulder," Journal of Rehabilitation Medicine, vol. 34, no. 2, pp. 91-95, 2002.

[25] Z. Dvir and J. Keating, "Reproducibility and validity of a new test protocol for measuring isokinetic trunk extension strength," Clinical Biomechanics, vol. 16, no. 7, article no. 599, pp. 627-630, 2001.

[26] G. K. Karataş, F. Gögüş, and J. Meray, "Reliability of isokinetic trunk muscle strength measurement," American Journal of Physical Medicine \& Rehabilitation, vol. 81, no. 2, pp. 79-85, 2002.

[27] X. W. Liang, Studyon isokinetic Strength and Grip Strength Vaildity of Middle School Boys, Hunan Normal University, Changsha, China, 2009.

[28] A. T. Harding, B. K. Weeks, S. A. Horan et al., "Validity and test-retest reliability of a novel simple back extensor muscle strength test," SAGE Open Medicine, vol. 5, pp. 1-9, 2017.

[29] Ministry of Education, “"National student's physical fitness standard" testing and reporting of work notifications," 2016, http://www.moe.edu.cn/publifiles/business/htmlfiles/moe/A17gggs/201605/151698.html,2016-4-22/2017-07-03.

[30] D. William, F. L. Mcardle, and V. L. Katch, Essentials of Exercise Physiology, Wolters, 5th edition, 2016.

[31] J. O. Kim, C. W. Meeler, and H. Ye, Factor analysis: statistical methods and application problems, Gezhi press, 2016.

[32] P. Patricia, N. Rethwisch, and D. Wiksten, "Reliability of the trunk lift in high school boys and girls," Measurement in Physical Education and Exercise Science, vol. 1, no. 2, pp. 145-151, 1997.

[33] J. Moreland, E. Finch, P. Stratford et al., "Interrater reliability of six tests of trunk muscle function and endurance," Journal of Orthopaedic \& Sports Physical Therapy, vol. 26, pp. 200-208, 1997.

[34] J. L. Gao, X. Liu, Y. Z. Jiang, H. L. Li, and M. Yoshiyuki, Physical Measurement, Beijing: People's sports press, 1989.

[35] C. Dawson, R. Croce, Q. Timuinn et al., "Reliability of the Nicholas manual muscle tester on upper body strength in children ages 8-10," Pediatric Exercise Science, vol. 4, no. 4, pp. 340-350, 1992.

[36] D. Cvejio, P. Tamare, and S. Ostojio, "Assessment of physical fitness in children and adolencents," Physical Education Sport, vol. 11, no. 2, pp. 135-145, 2013.
[37] J. C. Pinero, E. G. Artero, V. E. Romero et al., "Criterionrelated validity of field-based fitness tests in youth: asystenmatic review," British Journal of Sports Medicine, vol. 44, no. 44, pp. 934-943, 2011.

[38] W. J. Rutherford and C. B. Corbin, "Validation of criterionreferenced standards for tests of arm and shoulder girdle strength and endurance," Research Quarterly for Exercise and Sport, vol. 65, no. 2, pp. 110-119, 1994.

[39] T. A. Baumgartner, S. Oh, H. Chung, and D. Hales, "Objectivity, reliability, and validity for a revised push-up test protocol," Measurement in Physical Education and Exercise Science, vol. 6, no. 4, pp. 225-242, 2002.

[40] J. R. Fernandez-Santos, J. R. Ruiz, D. D. Cohen, J. L. GonzalezMontesinos, and J. Castro-Piñero, "Reliability and Validity of Tests to Assess Lower-Body Muscular Power in Children," The Journal of Strength and Conditioning Research, vol. 29, no. 8, pp. 2277-2285, 2015.

[41] J. Castro-Piñero, F. B. Ortega, E. G. Artero et al., "Assessing muscular strength in youth: usefulness of standing long jump as a general index of muscular fitness," The Journal of Strength \& Conditioning Research, vol. 24, no. 7, pp. 1810-1817, 2010.

[42] N. A. Tillin, M. T. G. Pain, and J. Folland, "Explosive force production during isometric squats correlates with athletic performance in rugby union players," Journal of Sports Sciences, vol. 31, no. 1, pp. 66-76, 2013.

[43] O. Radenković and M. M.Stanković, "Kinematic aramenter differences between the countermovement jump (CMJ) and squat jump(SJ)," Research in Kinesiology, vol. 40, no. 2, pp. 257261, 2012.

[44] Children's health fund with the Hong Kong education department sports group in Hong Kong, "School fitness rewards program teachers handbook," 2016, http://www.edb.gov.hk/ tc/curriculum-development/kla/pe/references_resource/spfas/ index.html.

[45] Singapore Sports Council, "National physical fitness award (NAPFA) [EB/OL]," 2016, https://en.wikipedia.org/wiki/ National_Physical_Fitness_Award.

[46] W. C. Zhao, "“Sports" course in Russia national education standards (1-4grades)," Physical Education, vol. 3, pp. 41-42, 2008.

[47] W. C. Zhao, “"Sports" course in Russia national education standards (5-9grades)," Physical Education, vol. 4, pp. 22-23, 2008.

[48] W. C. Zhao, “"Sports” course in Russia national education standards (10-11grades)," Physical Education, vol. 5, pp. 47-48, 2008. 


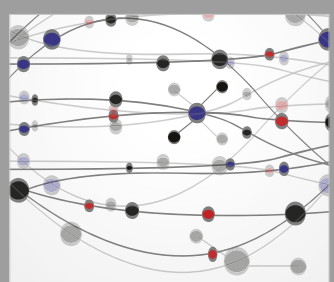

The Scientific World Journal
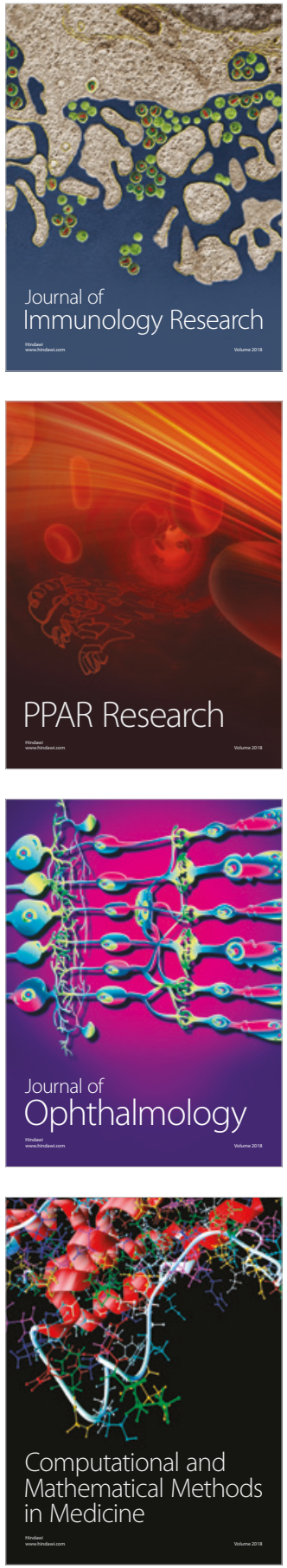

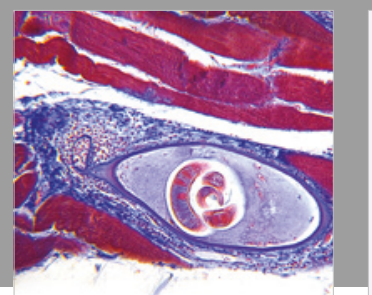

Gastroenterology Research and Practice

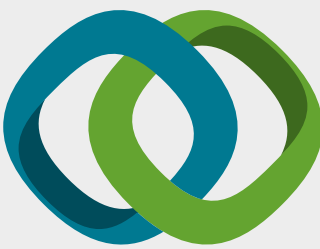

\section{Hindawi}

Submit your manuscripts at

www.hindawi.com
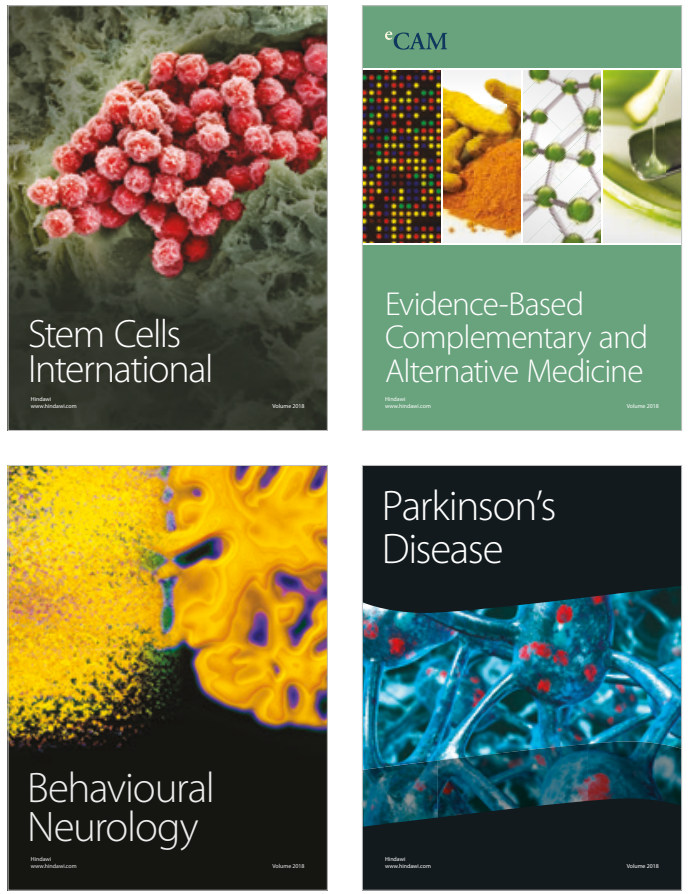

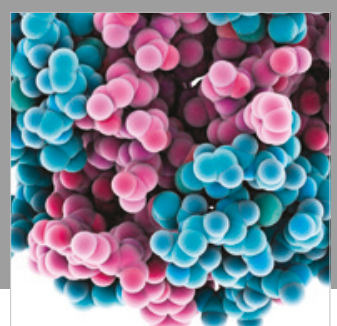

ournal of

Diabetes Research

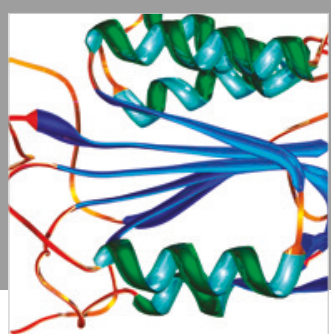

Disease Markers
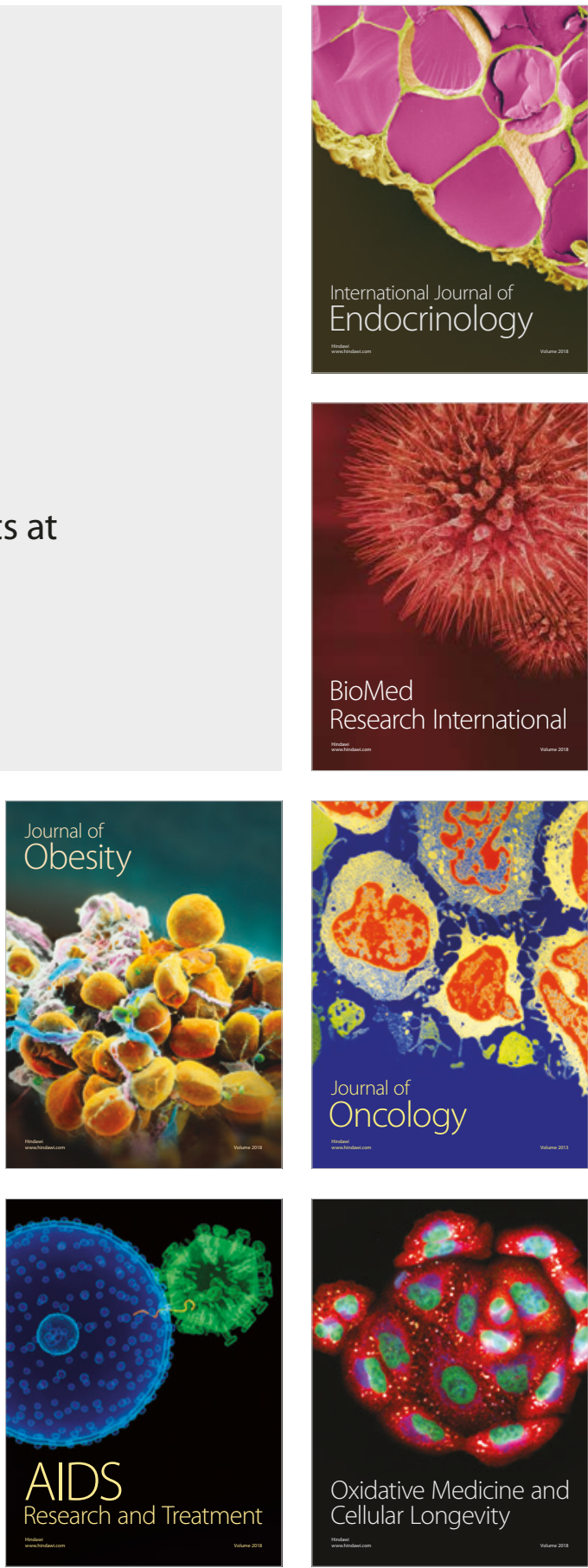